\title{
ROOM-TEMPERATURE DEPOSITION PROCESS AND CHARACTERIZATION OF AL-CUOx NANOSIZED THERMITE MATERIALS
}

\author{
${ }^{1}$ Larisa SOROKINA, ${ }^{1}$ Egor LEBEDEV, ${ }^{1}$ Dmitry IGNATOV, ${ }^{2}$ Roman RYAZANOV, ${ }^{2}$ Artem SYSA, \\ ${ }^{2}$ Yuriy SHAMAN, ${ }^{1}$ Dmitry GROMOV \\ ${ }^{1}$ National Research University of Electronic Technology, Zelenograd, Moscow, Russian Federation, \\ larisa.ivanovna95@gmail.com \\ ${ }^{2}$ Scientific Manufacturing Complex "Technological Centre", Zelenograd, Moscow, Russian Federation
}

https://doi.org/10.37904/nanocon.2019.8628

\begin{abstract}
In this work, a stable suspension recipe and the optimal mode for EPD process are presented. The possibility of precision control of the thermite material composition in electrophoretic deposition technology is considered. The wave combustion reaction occurs in the composition range from $17 \%$ to $53 \%$ wt. $\mathrm{CuO}_{x}$ content in deposited layer. The obtained $\mathrm{Al}-\mathrm{CuO}_{x}$ samples show high density of the released energy: $2407 \mathrm{~J} / \mathrm{g}$ in air atmosphere and $1954 \mathrm{~J} / \mathrm{g}$ in argon atmosphere measured by DSC. The velocity of combustion wavefront propagation determined by high-speed video camera reached $3.5 \mathrm{~m} / \mathrm{s}$.
\end{abstract}

Keywords: Thermite materials, powder mixtures, electrophoretic deposition, Al-CuO, wave combustion

\section{INTRODUCTION}

Thermite materials due to their energy properties demonstrate considerable research interest as a local heat source for different purposes of micro - and nanoelectronics: MEMS, micro jet engines, micro-initiators, 3d assembly of microelements, gas generator, information protection and much more [1-7]. Material's energy properties determined not only by the chemical composition but also by the geometric and morphological parameters. At present, thermite materials can be divided into two large groups: powder mixtures and multilayer structures [8]. Multilayer structures in most cases fabricated by magnetron or ion sputtering, and using an electron beam. The main disadvantages of these methods are the high cost of equipment and low process performance. On the other hand, powder mixtures can be quite simply obtained in large quantities, however, there is a problem related to the formation of these materials in the form of a thin layer on the substrate surface. One of the promising ways to resolve this problem is electrophoretic deposition (EPD) technology - a simple method that allows the deposition of multicomponent compositions on the conductive substrates surface from suspensions. The main advantages of this room-temperature technology are the forming of coatings with precisely controlled composition and the feasibility of local deposition onto patterned electrodes. This paper presents the features of electrophoretic deposition of $\mathrm{Al}-\mathrm{CuO}_{\mathrm{x}}$ nanosized thermite materials. Parameters that influence the combustion characteristics of the material and methods for their control using EPD technology were reviewed. The thermal effects and combustion properties of the prepared materials were studied using differential scanning calorimetry and high-speed video recording.

\section{EXPERIMENTAL}

In this work chemically pure isopropyl alcohol (99.8\%), nanopowders of Al with an average particle size of 90 - $110 \mathrm{~nm}$ and $\mathrm{CuO}_{x}$ with an average particle size of $50-80 \mathrm{~nm}$ were used for the suspension preparation. The $\mathrm{CuO}_{x}$ nanopowder contains phases $\mathrm{CuO}_{\text {and }} \mathrm{Cu}_{2} \mathrm{O}$ phases, the content of other elements is not more than $0.05 \mathrm{wt} . \% .100 \mu \mathrm{m}$ thick titanium foil was used as a substrate, which was preliminarily chemically etched in $\mathrm{HF}: \mathrm{HNO}_{3}: \mathrm{H}_{2} \mathrm{O}(1: 1: 4$ by volume) solution to remove the impurities and titanium oxide layer. Then the substrates were thoroughly washed in deionized water and dried in vapor of isopropyl alcohol. 
To prepare suspension nanopowder materials in a certain weight ratio were added to isopropyl alcohol. The nanopowder loading in all cases was $1 \mathrm{~g} / \mathrm{l}$ and the total suspension volume was $50 \mathrm{ml}$. The prepared suspension was sonicated for 40 minutes at a temperature below $22^{\circ} \mathrm{C}$.

EPD process was carried out in a potentiostatic mode in the electrophoretic cell, consisting of a reservoir with suspension, electrodes, and a DC source. Electrodes were fixed vertically at distance of $1 \mathrm{~cm}$ and deposition occurred on the anode (titanium foil). Stainless steel was used as a cathode.

The deposit mass was calculated by weighing the electrodes before and after deposition. Surface morphology and composition of received layers were controlled by scanning electron microscopy and energy dispersive X-ray analysis. Simultaneous studies of differential scanning calorimetry (DSC) and thermogravimetric (TGA) analysis were performed on TA Instruments $Q 600$ derivatograph. For these studies deposited $\mathrm{Al}-\mathrm{CuO}_{\mathrm{x}}$ material was separated from the substrate using a sapphire scraper and placed in a ceramic crucible $\left(\mathrm{Al}_{2} \mathrm{O}_{3}\right)$. The minimum weight of the material for DSC and TGA study was $3 \mathrm{mg}$. Heating was performed in argon and air atmospheres at a heating rate of $10^{\circ} \mathrm{C} / \mathrm{min}$ in the range from room temperature to $800^{\circ} \mathrm{C}$.

The velocity of combustion wavefront propagation was measured using a high-speed camera at $15000 \mathrm{fps}$. The combustion initiation in all cases was carried out using a low-power piezoelectric element. The specific density of thermite material samples for the combustion characteristics study was $0.9 \mathrm{mg} / \mathrm{cm}^{2}$ surface area. The sample was fixed in the vertical direction and the combustion was initiated in the lower region of the material. The wavefront propagation velocity is calculated from the known distance and measured time intervals.

\section{RESULTS AND DISCUSSION}

The successful deposition result depends on the suspension composition development and the selection of optimal process mode. The EPD process should be carried out from a stable suspension, which implies a welldispersed system. The deposition of dispersed (not agglomerated) particles will occur when the particles in the suspension are electrostatically stabilized. Proper solvent selection plays an important role in the stability of the suspension. The most important factors of solvent media are liquid dielectric permittivity, conductivity and viscosity. Also, the addition of various additives such as dispersing and charging agents can contribute to system stability. In the works [9-11], the deposition results of $\mathrm{Al}-\mathrm{CuO}_{x}$ thermite materials from a suspension based on ethyl alcohol are presented. The authors increased the suspension stability by adding a small amount of water, however, this adversely affected the deposit quality due to hydrolysis [10]. This work presents the deposition results from a stable suspension based on isopropyl alcohol without adding any additives.

In the first set of experiments, the voltage dependence that helps to choose the optimal mode of the deposition process was established. Surface morphology, density and mass of deposited material

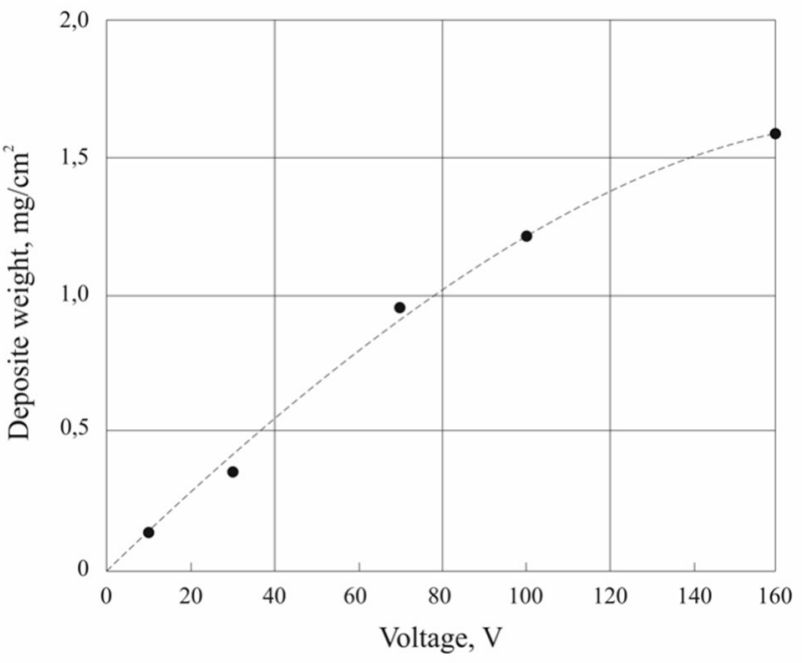

Figure 1 The Dependence of the deposited layer mass on the applied potential to the cell can be adjusted by changing applied potential and deposition time. For the test experiments deposition from suspension with $\mathrm{Al}: \mathrm{CuO}_{x}=1: 2$ weight ratio was carried out. Dependence of the deposited layer mass on the applied potential to the cell at the same deposition time (5 $\mathrm{min}$ ) is presented in Figure 1. 
Dependence indicates an increase in the deposition rate with increasing applied voltage, however, it is not linear. Due to the rapid flow of particles to electrode at a higher electric field a deposit layer forms with high porosity. This effect leads to material adhesion lowering; therefore, some deposit part can be desorbed both during the deposition process and during sample extraction from the suspension. In our case, it was visually observed that the applied voltage of $70 \mathrm{~V}$ corresponds to the most uniform depositing layer over the entire area. Figure 2 shows elemental mapping over the sample surface of $\mathrm{Al}-\mathrm{CuO}_{x}$ material deposited at a voltage of $70 \mathrm{~V}$.
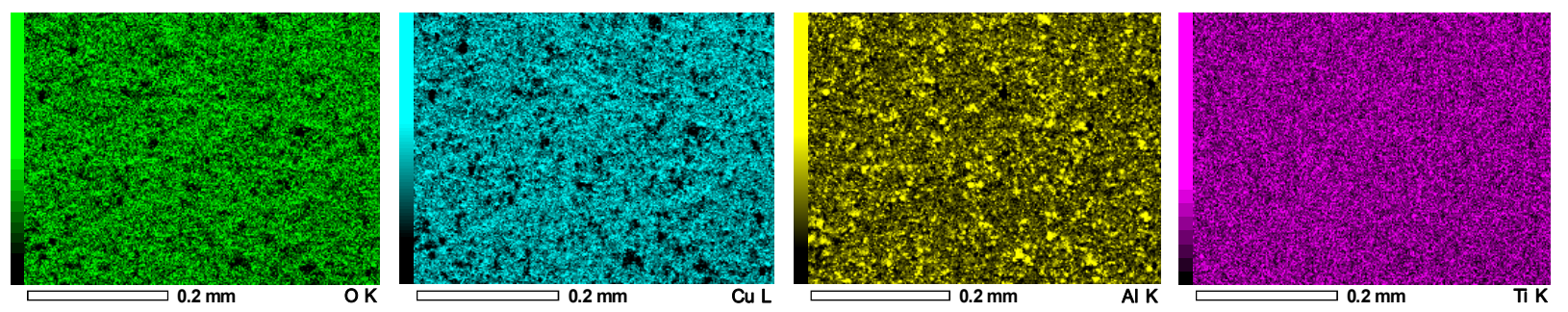

Figure 2 Elemental mapping of $\mathrm{Al}-\mathrm{CuO}_{x}$ material

The EDX analysis demonstrates uniform distribution of elements over the entire area. To assess the suspension stability the deposition of 6 samples sequentially from one suspension at $70 \mathrm{~V}$ and 15 min was performed. The results of this study are shown in Figure 3.

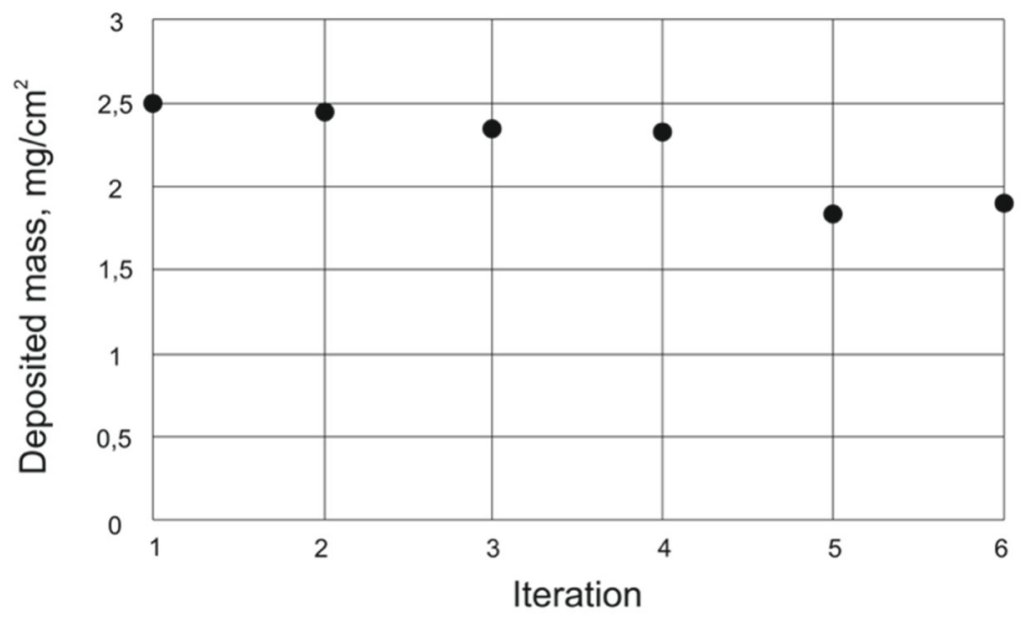

Figure 3 Change in deposit mass during sequential deposition from a suspension

The graph shows a gradual decrease in mass after each deposition cycle. During the deposition of the first 4 samples a change in the mass value by $5 \%$ was observed, and then the deposited layer mass down $25 \%$, which is explained by a decrease in the particles concentration in the suspension and, therefore, a decrease in the deposition rate (solid loading in suspension is reduce down $20 \%$ ). The total process time was more than 120 minutes, taking into account the time delay for electrodes replacement. While it was previously noted that suspension stability period is limited by after 30 minutes [10].

Next, a series of experiments to investigate the effect of the suspension composition on the deposited layer composition was produced. The set of suspensions with the same powder load, but with different components ratios (from oxidizer-poor to oxidizer-rich) was prepared. Further, the deposition process was carried out at $70 \mathrm{~V}$ and $10 \mathrm{~min}$. Figure 4 shows the dependence of the deposit composition in the weight equivalent, which was determined by EDX analysis on the initial suspension composition. 


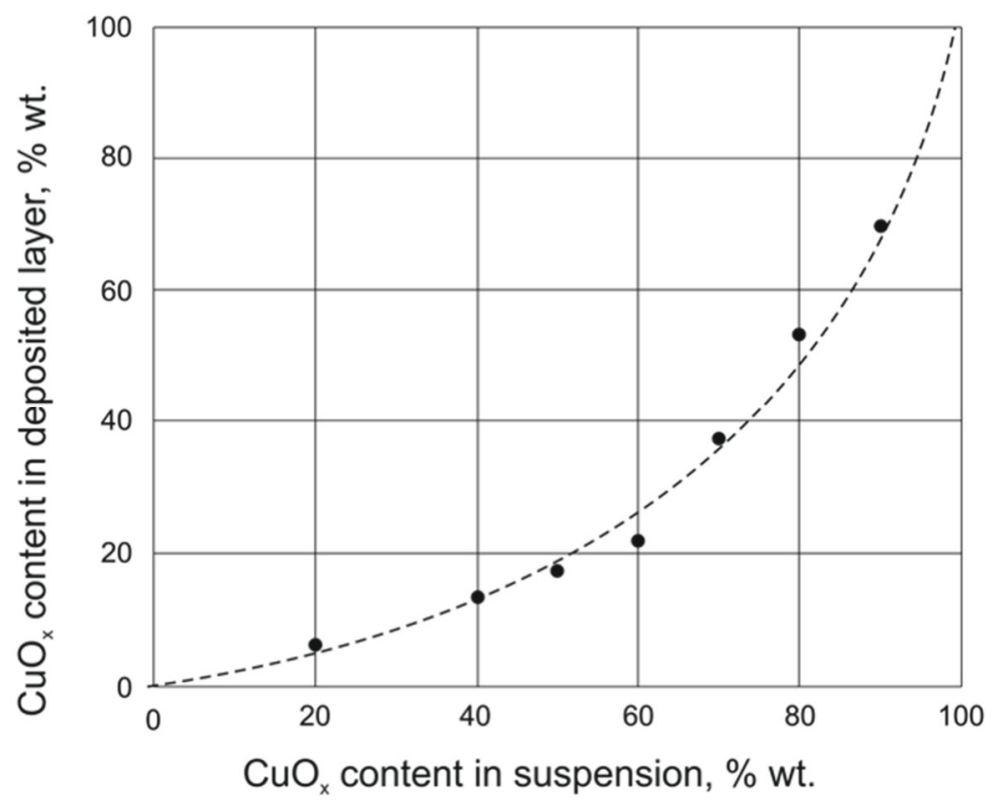

Figure 4 Dependence of the deposit composition on the $\mathrm{CuO}_{\mathrm{x}}$ content in initial suspension

The graph shows a deviation from the linear correlation between the suspension and deposit compositions, which is explained by the higher electrophoretic mobility of aluminum particles in isopropyl alcohol. This graph allows to determine the suspension composition for material deposition with the required components ratio. The same set of obtained samples was exposed to a low-power piezoelectric element. The initiation of the wave combustion occurs in the composition range from $17 \%$ to $53 \%$ wt. $\mathrm{CuO}_{x}$ content in deposit. Figure 5 shows the combustion process storyboard of the $\mathrm{Al}_{-\mathrm{CuO}}$ material formed from $60 \% \mathrm{wt}$. $\mathrm{CuO}_{x}$ suspension, which corresponds to $23 \%$ wt. $\mathrm{CuO}_{x}$ content in the deposit. The combustion wavefront propagates uniformly over the sample entire area at the same speed. The velocity of combustion wavefront propagation was $3.5 \mathrm{~m} / \mathrm{s}$, which is quite high for a given weight value compared to previously published work [11].
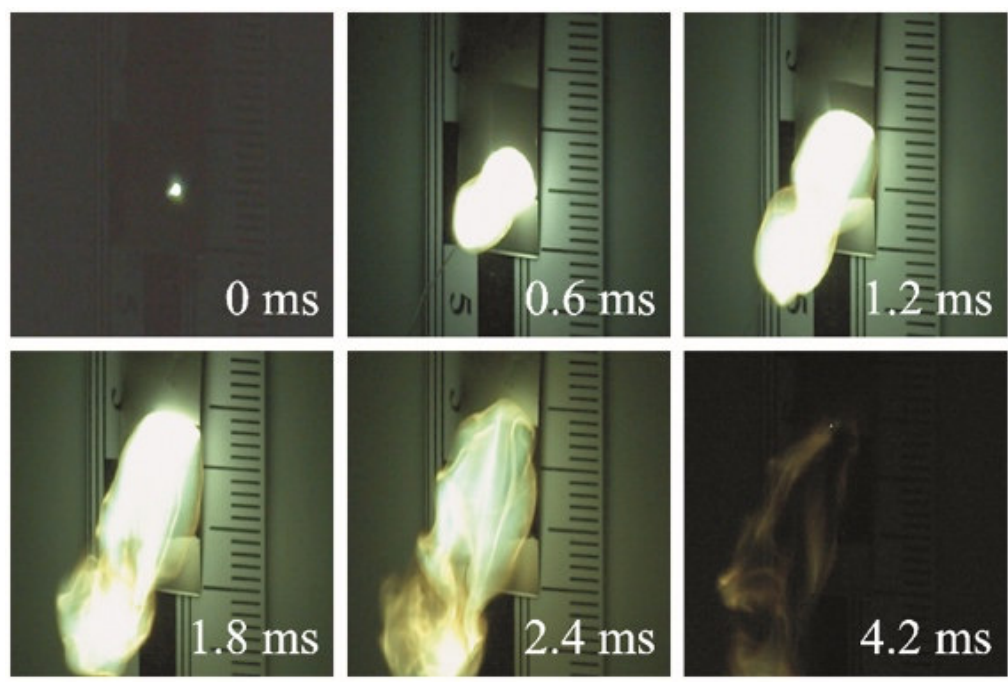

Figure 5 Storyboard of combustion process of the $\mathrm{Al}-\mathrm{CuO}_{x}$ material with $23 \%$ wt. $\mathrm{CuO}_{x}$ content

Thermite materials with $23 \%$ wt. $\mathrm{CuO}_{x}$ content were studied by DSC and TGA. The DSC and TGA results in argon and air atmosphere presented in Figure 6. 


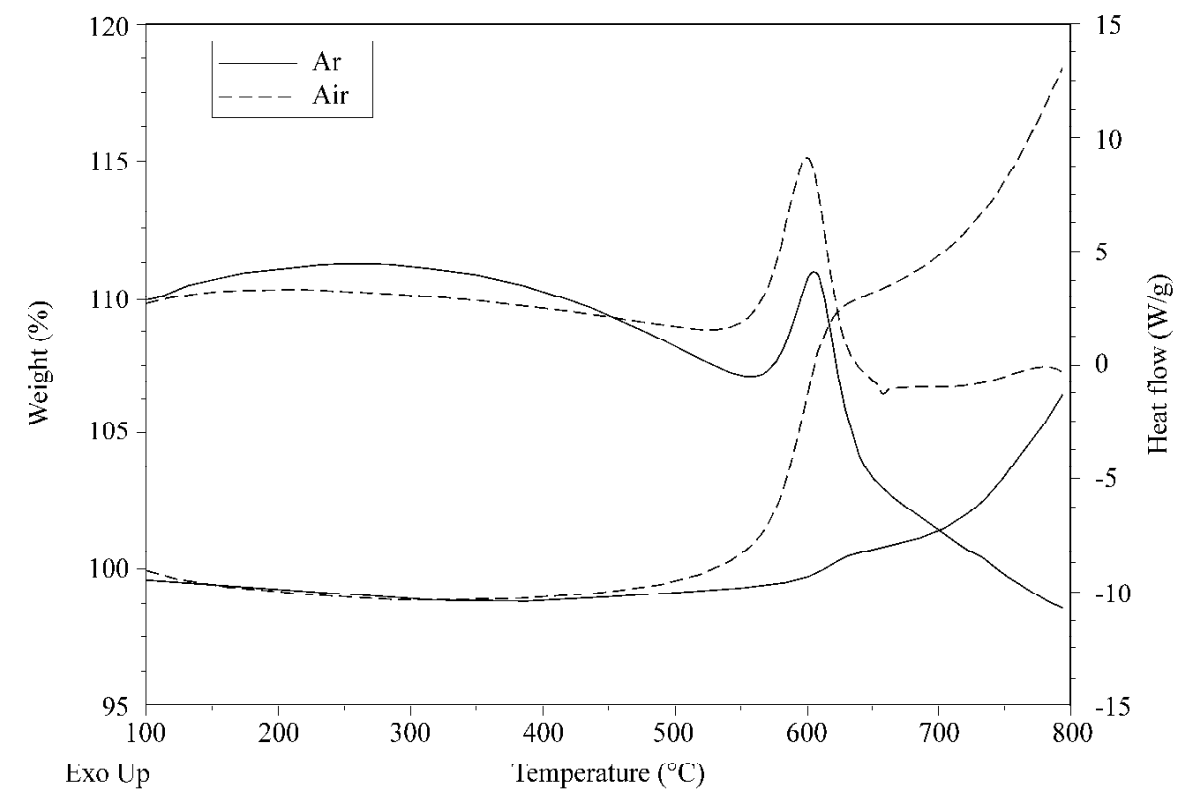

Figure $6 \mathrm{DSC}$ and TGA curves for the $\mathrm{Al}-\mathrm{CuO}_{x}$ material with $23 \%$ wt. $\mathrm{CuO}_{x}$ content received in argon and air atmosphere

One main exothermic peak in the range from 550 to $650{ }^{\circ} \mathrm{C}$ was detected on the curves, which corresponds to the chemical reaction of the material components. TGA study results in air atmosphere show that in this temperature range the sample mass increased by $10 \%$. This phenomenon can be explained by the interaction of aluminum with oxygen from the atmosphere. Despite the fact that the peaks differ in intensity, their position is the same, which indicates that chemical interaction between aluminum and copper oxide takes place according to the same mechanisms in air and argon atmosphere. The values of the thermal effects in air and argon atmosphere differ by only $20 \%$ (2407 and $1954 \mathrm{~J} / \mathrm{g}$ respectively). It can be assumed that the combustion self-propagating reaction of the material can occur in an airless space or in an inert environment, which can significantly expand the range of potential applications.

\section{CONCLUSION}

In this work, it was found that the porosity of the deposited material increases at high values of the applied potential to the EPD cell, as a result, adhesion decreases and some deposit part can be desorbed. Based on these results, the optimal voltage for the process was selected. Optimization of the suspension composition allowed to increase the time of the suspension stability for nonstop deposition up to $60 \mathrm{~min}$. The possibility of precision control of the thermite material composition by changing the suspension content was demonstrated. The composition range of thermite materials in which wave combustion occurs has been determined (from 17 $\%$ to $53 \%$ wt. $\mathrm{CuO}_{x}$ content in deposit). The results of high-speed video recording showed that the combustion wavefront propagates uniformly over the sample entire area at the same speed. DSC and TGA results showed an insignificant change in the total heat release measured in air and argon atmosphere. This opens up additional possibilities for using $\mathrm{Al}-\mathrm{CuO}_{x}$ thermite materials obtained by the EPD method in an airless or inert environment.

\section{ACKNOWLEDGEMENTS}

This work was supported by the Russian Federation President's grant (MK-1262.2019.8) 


\section{REFERENCES}

[1] BRAEUER, J., BESSER, J., Wiemer, M., and GESSNER, T. A novel technique for MEMS packaging: Reactive bonding with integrated material systems. Journal of Sensors and Actuators. 2012. vol. 188, pp. 212-219.

[2] ZHU, W., Fengshun, W., Baihui, W., Eric, H., Paul, W., Changqing, L., Weisheng, X. Microstructural and Mechanical Integrity of $\mathrm{Cu} / \mathrm{Cu}$ Interconnects Formed by Self-Propagating Exothermic Reaction Methods. Journal of Microelectronic Engineering. 2014. vol. 128, pp. 24-30.

[3] SIMÕES, S., VIANA, F., KOÇAK, M., RAMOS, A. S., VIEIRA, M. T., F. VIEIRA, M. Microstructure of Reaction Zone Formed During Diffusion Bonding of TiAl with Ni/Al Multilayer. Journal of Materials Engineering and Performance. 2012. vol. 21, no. 5, pp. 678-682. https://doi.org/10.1007/s11665-012-0144-0.

[4] LONG, Z., DAI, B., TAN, S., WANG, Y., WEI, X. TRANSIENT Liquid Phase Bonding of Copper and Ceramic $\mathrm{Al}_{2} \mathrm{O}_{3}$ by $\mathrm{Al} / \mathrm{Ni}$ Nano Multilayers. Journal of Ceramics International. 2017. vol. 43, no. 18, pp. 17000-17004.

[5] BARAS, F., TURLO, V., POLITANO, O. Dissolution at Interfaces in Layered Solid-Liquid Thin Films: A Key Step in Joining Process. Journal of Materials Engineering and Performance. 2016. vol. 25, no. 8, pp. 3270-3274.

[6] IEE, K., KIM, D., SHIM, J., BAE, S., SHIN, D. J., E. TREML, B., YOO, J., HANRATH, T., KIM, W., LEE, D. C. Formation of Cu Layer on Al Nanoparticles During Thermite Reaction in Al/CuO Nanoparticle Composites: Investigation of Off-Stoichiometry Ratio of Al and CuO Nanoparticles for Maximum Pressure Change. Journal of Combustion and Flame. 2015. vol. 162, no. 10, pp. 3823-3828.

[7] NICOLlet, A., SAlVAGNAC, L., BAIJOT, V., ESTĖVE, A., and ROSSI, C. Fast Circuit Breaker Based on Integration of Al/CuO Nanothermites. Journal of Sensors and Actuators A: Physical. 2018. vol. 273, pp. $249-255$.

[8] ROGACHEV, A. S., MUKASYAN, A. S. Combustion of Heterogeneous Nanostructural Systems (Review). Journal of Combustion, Explosion, and Shock Waves. 2010. vol. 46, no. 3, pp. 243-266.

[9] SULLIVAN, K., KUNTZ, J., GASH. A., Electrophoretic Deposition and Mechanistic Studies of Nano-Al/CuO Thermites. Journal of Applied Physics. 2010. vol. 112, no. 2

[10] SULLIVAN, K., WORSLEY, M., KUNTZ, J., GASH, A. Electrophoretic Deposition of Binary Energetic Composites. Journal of Combustion and Flame. 2012, vol. 159, no. 6, pp. 2210-2218.

[11] SULLIVAN, K., Zhu, C., TANAKA, D., KUNTZ, J., DUOSS, E., GASH, A. Electrophoretic Deposition of Thermites onto Micro-Engineered Electrodes Prepared by Direct-Ink Writing. Journal of Physical Chemistry. 2012. vol. 117, no. 6 , pp. $1686-1693$. 